\title{
Consensus exercise on domains in psoriatic arthritis
}

\section{D Gladman}

Ann Rheum Dis 2005;64(Suppl II):ii1 13-ii1 14. doi: 10.1136/ard.2004.030882

\begin{abstract}
Recent studies with biological therapy in psoriatic arthritis (PsA) have highlighted the need for validated and widely accepted assessment tools and outcome measures for this disease. A Delphi process was established through the CASPAR group where domains for assessment of PsA in clinical trials, longitudinal studies, and rehabilitation were identified. Although the process reduced the list of possible domains to $\sim 12$, it was not able to detect those that would be most important. Moreover, skin assessment was left out. A further study through the GRAPPA group subsequently identified the following domains: inflammation (peripheral joints, axial skeleton, physician global assessment), other features (dactylitis, enthesitis), skin and nails, imaging, biomarkers, and patient derived indices (pain, quality of life, itch, function), as important in the assessment of patients with PsA. These domains require further refining, and instruments to measure the items need to be developed.
\end{abstract}

$\mathrm{P}$ soriatic arthritis (PsA) has been considered as a mild, relatively rare disease and has not been studied extensively with regard to assessment of clinical and radiological features. There are no widely accepted criteria for classification or diagnosis of the disease, and there are no widely accepted valid assessment tools or criteria for response in clinical trials.

As a first step to identifying domains which should be assessed in patients with PsA, a Delphi exercise was recently carried out among members of the CASPAR (ClASsification of Psoriatic ARthritis) group. This exercise produced lists of domains that would be considered for disease modifying antirheumatic drugs, symptom modifying antirheumatic drugs, rehabilitation, and longitudinal observational cohort studies. ${ }^{1}$ As a result of the study, the number of possible domains was reduced from a list of 26 to about a dozen. However, the study did not provide enough consensus on items that were considered less important. Moreover, there was a concern that the participants included only rheumatologists, and there was one obvious omission of the skin assessment as a domain. It was also noted that it would be advantageous to further discuss these domains in a face to face meeting of rheumatologists, dermatologists, and patients. Such an opportunity presented itself during the meeting of the Group for Research and Assessment of Psoriasis and Psoriatic Arthritis (GRAPPA) in New York on 15 August 2003, and an exercise to achieve consensus on domains for studies in PsA was developed for the group assembled for this meeting.

Before the New York consensus exercise, the results of the Delphi exercise were reviewed. In addition, a review of the domains relevant to PsA was presented. The span of the domains includes clinical assessment, imaging, biomarkers, patient derived features, and outcomes relevant to patients with PsA. ${ }^{2}$
Under clinical assessment the degree of inflammation in both peripheral joint disease and axial disease needs to be included. The assessment of clinical damage may need to be included as well. In addition, physician global and patient global assessments would be important. Other clinical features of PsA also require assessment including dactylitis, which could be acute or chronic, enthesitis, and tendinitis. Skin assessment including type and extent of psoriasis, and presence, type, and extent of nail lesions are important domains in the assessment of patients with PsA.

Although conventional radiography has been considered an important method of defining damage in PsA, recent advances in imaging suggest that ultrasound and magnetic resonance imaging may also be relevant in the assessment of inflammation in patients with joint disease. ${ }^{2}$ Acute phase reactants such as the erythrocyte sedimentation rate (ESR) and $\mathrm{C}$ reactive protein (CRP) may also be an important domain, as may be other biomarkers such as cytokines, which are clearly relevant to inflammation and may vary with disease activity and therapy, and genetic markers, which may identify patients with a particular disease pattern and response to therapy.

Patient derived features including pain assessment, fatigue, and quality of life, may be related to either the joint or skin disease, and the resultant disability may also reflect either joint or skin disease, or both. Outcomes to be considered include clinical and radiological damage, death, disability, and drug toxicity.

\section{THE EXERCISE}

The objectives of the group exercise in New York were as follows:

- outline domains in PsA

- achieve consensus on the domains

- identify instruments for each domain

- identify areas requiring further research.

The process involved three breakout groups (table 1). Each group had a leader and a scribe and had to develop a list of domains and vote on the domains that should be included in

Table 1 Participants in consensus exercise

\begin{tabular}{llll}
\hline & Group A & Group B & Group C \\
\hline Leader & D Gladman & P Mease & P Nash \\
Scribe & A Kavanaugh & P Helliwell & C Antoni \\
Participants & D Chandler & M A Khan & G Zimmerman \\
& G Krueger & M Lebwohl & J T Elder \\
& F van den Bosch & D Baeten & D Clegg \\
& C Ritchlin & J Braun & J Smolen \\
& R Landewé & L Espinoza & J Kalden \\
Sponsors & C Bingham & S Reddy & P Kaltwasser \\
(no vote) & A Beutler & E Dolce & C Schweiger \\
& M Danzig & S Stevens & S Chioato \\
& & M Temples & \\
\hline
\end{tabular}




\begin{tabular}{|c|c|c|}
\hline Domain & Item & Instrument \\
\hline Joint inflammation & $\begin{array}{l}\text { Peripheral joints } \\
\text { Axial skeleton } \\
\text { Physician global }\end{array}$ & $\begin{array}{l}\text { ACR joint count, } 68 \text { joints } \\
\text { To be determined } \\
10 \mathrm{~cm} \text { VAS }\end{array}$ \\
\hline Other features & $\begin{array}{l}\text { Dactylitis } \\
\text { Enthesitis }\end{array}$ & $\begin{array}{l}\text { To be determined } \\
\text { To be determined }\end{array}$ \\
\hline Skin & $\begin{array}{l}\text { Skin psoriasis extent } \\
\text { Individual lesion }\end{array}$ & $\begin{array}{l}\text { To be determined } \\
\text { To be determined }\end{array}$ \\
\hline $\begin{array}{l}\text { Nails } \\
\text { Imaging (damage) } \\
\text { Biomarkers }\end{array}$ & $\begin{array}{l}\text { Type extent } \\
\text { Hands, feet, pelvis } \\
\text { CRP, ESR }\end{array}$ & $\begin{array}{l}\text { To be determined } \\
\text { Radiography }\end{array}$ \\
\hline Patient derived & $\begin{array}{l}\text { Pain } \\
\text { Quality of life related } \\
\text { to joint and skin } \\
\text { disegse }\end{array}$ & $\begin{array}{l}\text { Patient global } \\
\text { SF-36; DLQ }\end{array}$ \\
\hline & & $\begin{array}{l}\text { To be determined } \\
\mathrm{HAQ}\end{array}$ \\
\hline
\end{tabular}

ACR, American College of Rheumatology; CRP, C-reactive protein; DLQI, Dermatology Life Quality Index; ESR, erythrocyte sedimentation rate; $H A Q$, Health Assessment Questionnaire; VAS, visual analogue scale.

the assessment of patients with PsA. If possible, each group was to identify instruments for each domain. The scribe from each group then presented the results of their group's deliberations at the combined session. Each group took a different approach to the problem.

Group A started from the domains from the Delphi exercise and allowed everyone the opportunity to add other domains as they saw necessary. Members developed a list of items and then anonymously scored them, 1 being the least important and 5 being the most important. The ranking revealed that skin (Psoriasis Area and Severity Index (PASI) and target lesion), patient global (visual analogue scale (VAS)), peripheral inflammatory arthritis (tender and swollen joints 68/66), physical function (Health Assessment Questionnaire (HAQ)), quality of life (short form (SF)-36, Dermatology Life Quality Index (DLQI)), physician global (VAS), damage as assessed by imaging (radiographs of hands, feet, AP pelvis), and pain (VAS) were the most important domains. Nail, acute phase reactions, deformity, axial involvement, dactylitis, biomarkers, and enthesitis were the next series of domains, and fatigue, health economic assessments, and morning stiffness received the lowest scores.

Group B identified peripheral arthritis, axial arthritis, entheseal disease, dactylitis, skin, and nails as important domains in the clinical assessment of PsA. From an imaging point of view plain radiography was thought to be important with a minimum core set to include hands, feet, and pelvis. Biomarkers, acute phase response, patient derived indices, measures of pain, fatigue, quality of life, function, and itch were also considered important.

Group C included a disease activity score (tender and swollen joint count using 68/66 joint count), an acute phase reactant (CRP), physician global (VAS), patient global (VAS), and pain (VAS). There was some discussion about how to measure activity with dactylitis, enthesitis, and spinal involvement, and the group suggested that a yes/no criterion would be appropriate to start with and a subsequent individual score if present. For the skin, PASI or National Psoriasis Foundation (NPF), and for function and quality of life, the HAQ and SF-36 were suggested; for damage, plain $x$ rays including hands, feet, and AP pelvis were suggested. The group also added the presence of extra-articular disease and uveitis.

\section{RESULTS AND DISCUSSION}

The final recommendation for the domains and available instruments is shown in table 2.

The following domains were proposed as a research agenda:

- assessment of spinal involvement, dactylitis, tendinitis, and enthesitis

- assessment of extent and severity of nail involvement

- evaluation of cytokines and other biomarkers, including genetic markers

- evaluation of fatigue.

It was further felt that the assessment of outcome in terms of damage, both clinical and radiological, and the assessment of disability required further study. It was felt that for drug toxicity the tools used for the assessment of other rheumatological disorders were appropriate.

Thus, this group exercise has achieved its objective of developing a consensus on the domains necessary to evaluate patients with PsA. These domains, including assessment of joint inflammation, inflammation in other areas, biomarkers, imaging, and patient derived indices, would be important to include in all studies of PsA. For some of the domains, there are already appropriate instruments, such as the American College of Rheumatology (ACR) joint count for peripheral joint inflammation, and the CRP or ESR for inflammatory biomarkers. Other domains, such as the assessment of other features of PsA or the spinal assessment, require either the development of new instruments or the validation of existing instruments. The next step will be to confirm these domains in a larger group and identify the instruments necessary to measure these domains.

Correspondence to: Dr D D Gladman, University of Toronto, Toronto Western Research Institute, Psoriatic Arthritis Program, University Health Network, Centre for Prognosis Studies in the Rheumatic Diseases, Toronto Western Hospital, 399 Bathurst St. ECW 5-034B, Toronto, Ontario, M5T 2S8, Canada; dafna.gladman@utoronto.ca

\section{REFERENCES}

1 Taylor WJ. Preliminary identification of core domains for outcome studies in psoriatic arthritis using Delphi methods. Ann Rheum Dis 2005;64(suppl II):iii 10-2.

2 Gladman DD, Helliwell P, Mease PJ, Nash P, Ritchlin C, Taylor W. Assessment of patients with psoriatic arthritis. A review of currently available measures. Arthritis Rheum 2004;50:24-35. 